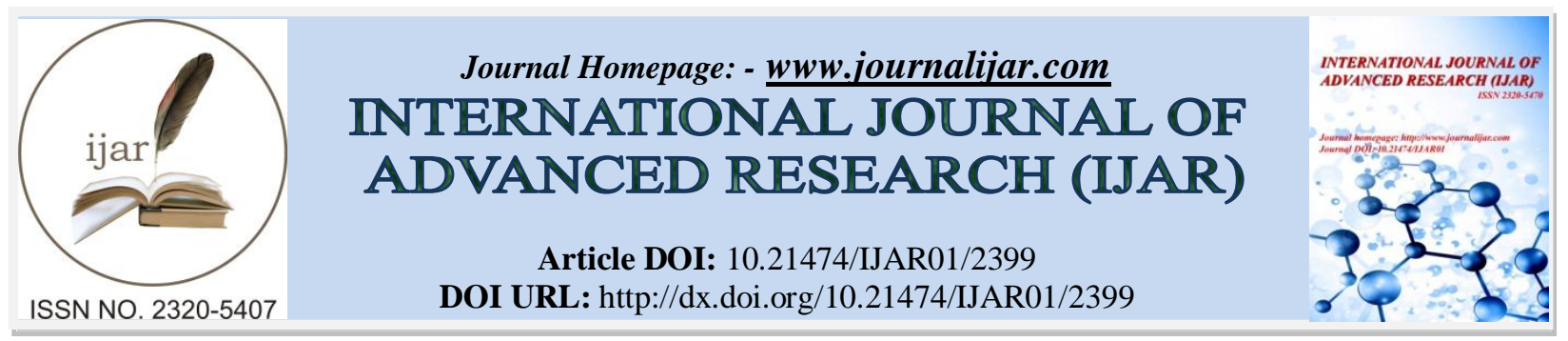

RESEARCH ARTICLE

\title{
A STUDY TO DETERMINE THE LEVEL OF CPR AWARENESS IN MECCA PROVINCE.
}

DR. Abdullah H. Khan and Dr. Abdulhameed A. Almoalem.

Faculty of Medicine at Umm Al-Qura University, Makkah, Saudi Arabia.

\section{Manuscript Info}

Manuscript History

Received: 19 October 2016

Final Accepted: 20 November 2016

Published: December 2016

Key words:-

\section{Abstract}

Cardiopulmonary resuscitation (CPR) is an important component in rescuing patient with cardiac arrest. It aims to preserve brain function, which can be lifesaving and may increase the rate of survival two to three times comparing to those who did not receive CPR. Based on WHO statistics in 2006, $80 \%$ of cardiac arrests occur at home and most of arrested patients died before reaching the hospital.

In recent years, there has been an increasing interest in the field of CPR education that leads to increase in surviving for patient with CPR training worldwide. In Saudi Arabia, the ministry of health ordered all hospitals to have a center for CPR training. In addition,the M.O.H. recently started to require that all medical personnel working during the pilgrimage season must be holders of a valid certificate in CPR.

However, Non-medical personnel are rarely trained in cardiopulmonary resuscitation (CPR) in Saudi Arabia. Moreover, many people who die in the community either suddenly or expectedly are not brought to a hospital for resuscitation.

In this study, we will determine the level of awareness of CPR in Mecca Province and the quality of response to arrested cases in the community. A cross sectional study has been conducted among 562 of Mecca province residents. The study assessed their knowledge in CPR and the response to arrested cases. For those who had CPR training before, the study evaluated their recent knowledge and expected response.

The study offers a good opportunity to measure the recent CPR awareness level of Mecca residents and direct future efforts for the demand of health educational opportunities dedicated to the community.

Copy Right, IJAR, 2016,. All rights reserved.

\section{Background:-}

For further optimization of rescuing patient with cardiac arrest in Mecca, High level of CPR awareness issupposed to beachieved in the community.

\section{Introduction:-}

Cardiopulmonary resuscitation (CPR) is an important component in the rescuing patient with cardiac arrest by creating artificial circulation that pump blood through the heart to vital organs and providing breaths by mouth or 
through utilizing device. It aims to preserve brain function which can be lifesavingand may increase the rate of survival two to three times comparing to those who didn't receive CPR[1-5].

The high mortality associated with heart diseases is major public health problem worldwide that increase the demand of CPR awareness in every community. In Saudi Arabia, about25,000 of deaths each year is caused by cardiovascular disease. Based on WHO statistics, $80 \%$ of cardiac arrests occur at home and many of the arrested patients died before reaching the hospital $[1,6,7]$.

In recent years, there has been an increasing interest in the field of CPR education that leads to increase in surviving for patient with BLS (or CPR) training worldwide [8-10]. In Saudi Arabia, the ministry of health ordered all hospitals to have a center for CPR training. Also the M.O.H. recently started to require that all medical personnel working during the pilgrimage season must be holders of a valid certificate in CPR[11].

However,Non-medical personnel are rarely trained in cardiopulmonary resuscitation (CPR) in Saudi Arabia. Many people who die in the community, either suddenly or expectedly are not brought to a hospital for resuscitation[12]. Moreover, patient access to available ambulance service is poor, and a centralized control center for medical emergencies is not established. Most arrested victims are consequently transported to a hospital in private vehicles.

\section{Research Question:-}

What is the level of awareness of CPR in Mecca Province?

\section{Objective:-}

To determine the level of Awareness of CPR in Mecca Province and the quality of response to arrested cases in the community.

\section{Methodology:- \\ Study design:-}

A cross sectional study was conducted among Mecca residents. The electronicquestionnaireassessedtheir knowledge in CPR and the steps of CPR were evaluated separately.In addition, the response to arrested cases has been assessed. For those who had CPR training before, the questionnaire also evaluated their recent knowledge and expected response.

\section{Study population:-}

The study targeted permanent Mecca residents above the age 20 years old.

\section{Study Sample:-}

AllMecca residentsof both genderswho are suitable for inclusion and exclusion criteria.

\section{Sample selection:-}

The questionnaire delivered to the population through invitations in social media to all Makkah province social media users.

Inclusion criteria:- All Mecca residents above the age 20 years old will be invitedto participate in the questionnaire.

Exclusion criteria:- Mecca residents who are below the age 20 years old will be excluded. Mecca visitors and temporary residents will not be included too.

\section{Sample size:-}

The total number of Mecca residents above the age of twenty is 3,663,387 residents according the central department of statistics and informatics 2010. Using a confidence level of $95 \%$ and a marginal error of five, the target sample size will be around 600 residents in our cross sectional questionnaire.

\section{Study variables:-}

Quality of CPR Knowledge: (previous training, steps of CPR and perception of CPR importance). 


\section{Data collection:-}

The responses collected from volunteered participants over twomonthsassessing the following: Previous CPR training, the perception of its importance, the steps in performing CPR and the personal demand for CPR in family. The online survey targeted all social media users living in Makkah.

\section{Measurement tool:-}

A scale of CPR awareness was defined to measure the quality of CPR knowledge.

\section{Data analysis:-}

Data has been analyzed using SPSS. Significance level of 0.05 is used with a confidence level of $95 \%$ and confidence interval of one.

\section{Result:-}

The study was conducted onMakkah province residents whom are above the age of twenty year old. The electronic survey was answered by 583 respondents. 31 responses have been excluded as they have been answered either by residents outside of Makkah province or residents below the age of twenty year old. The total percentage of respondents who are either working or studying in the medical field is 51.8\%. Among those who works or study outside the medical field, only $35.8 \%$ had a previous CPR training. Using a confidence level of $95 \%$, there was a significant difference in CPR awareness between respondents in medical field and respondents outside.

CPR training course was the main aid for the aware population for $56.6 \%$ respondents. The assessment for arrested cases for the need of CPR and initial rescue steps have been evaluated among those who had CPR training and 98.77\% identified the need of CPR for the arrested cases correctly. However, only $49.28 \%$ of CPR trained population was able to recall the initial steps accurately while $61.9 \%$ was satisfied about their CPR knowledge. 94.2\% of non CPR trained population has the desire to get training. The reason behind the lack of training was referred by $49.1 \%$ as no training centers were known and $31 \%$ respondents were ignorant for the importance of CPR. Among trained population working in the medical field and outside the field, the training was an employment requirement for $45.7 \%$ and $11.1 \%$ respondents respectively.

\section{Discussion:-}

Because of the few health educational opportunities dedicated to our community,thelevel of community awareness of CPR was expectedto be low. The result showed a significant lack of CPR awareness among the community outside the medical field. The high demand for extensive future community awareness program was expected also. Moreover, most of the non trained sample realize the effectiveness of the CPR in rescuing arrested patients and showed an interest for future training. However, the lack of community based CPR training centers was the main referred cause of lack of training.

A similar study in 2006 at king Saud university in Riyadh found that among 2250 subjects, $31 \%$ did not have any previous information about CPR, other $69 \%$ with previous information $85 \%$ of them feel that their information is not sufficient while $10 \%$ feel it adequate[13]. In Makkah province, the results showed a close level of CPR awareness that has been measured previously in Riyadh. However, the level of awareness would be worse than the measured responses as nearly educated respondents represent most of social media users.

Based on the recent level of CPR awareness in Makkah province residents, we recommend that future efforts should be focused on: Education through ministry of education as part of curriculum and training of the community by ministry of health and Saudi Red Crescent Authority. Increasing the quality of training in the accredited centersis recommended especially in the practical part. Educational simulation of CPR cases can help to improve the level of knowledge among trainees as most of them lack the clinical exposure. Medical students should be part of awareness through campaigns or free training programs. The training has been agreed by most of the respondents should to be a graduation requirement to all university students and employment prerequisite. 


\section{References:-}

1. Ong, E.H., Improving the quality of CPR in the community. Singapore Med J, 2011. 52(8): p. 586-91.

2. Sipsma, K., B.A. Stubbs, and M. Plorde, Training rates and willingness to perform CPR in King County, Washington: a community survey. Resuscitation, $2:(5) 82$.011p. 564-7.

3. Chen, Z.Q., et al., Awareness and attitudes of Chinese students towards cardiopulmonary resuscitation. Emerg Med J, 2010. 27(12): p. 907-10.

4. Fredriksson, M., J. Herlitz, and G. Nichol, Variation in outcome in studies of out-of-hospital cardiac arrest: a review of studies conforming to the Utstein guidelines. Am J Emerg Med, 2003. 21(4): p. 276-81.

5. Auble, T.E., J.J. Menegazzi, and P.M. Paris, Effect of out-of-hospital defibrillation by basic life support providers on cardiacarrest mortality: a metaanalysis. Ann Emerg Med, 1995. 25(5): p. 642-8.

6. Herlitz, J., et al., Characteristics and outcome among patients having out of hospital cardiac arrest at home compared with elsewhere. Heart, 2002. 88(6): p. 579-82.

7. Lund-Kordahl, I., et al., Improving outcome after out-of-hospital cardiac arrest by strengthening weak links of the local Chain of Survival; quality of advanced life support and post-resuscitation care. Resuscitation, 2010. 81(4): p. 422-6.

8. Noc, M., et al., Prezivetje bolnikov z zastojem srca izven bolnisnice $v$ Ljubljani = Survival of patients with outof-hospital cardiac arrest in Ljubljana. Urgentna medicina, 1997: p. 123-129.

9. Tadel, S., M. Horvat, and M. Noc, Treatment of out-of-hospital cardiac arrest in Ljubljana: outcome report according to the 'Utstein' style. Resuscitation, 1998. 38(3): p. 169-76.

10. Marenco, J.P., et al., Improving survival from sudden cardiac arrest: the role of the automated external defibrillator. JAMA, 2001. 285(9): p. 1193-200.

11. Seraj, M.A.A.-N., Mansour; Harvey, Paul J., Achievements With Cardiopulmonary Resuscitation In The Last 21 Years In The Kingdom Of Saudi Arabia. Internet Journal of Health, 2008.7 (2): p. 3.

12. Conroy, K.M. and S.W. Jolin, Cardiac arrest in Saudi Arabia: a 7-year experience in Riyadh. The Journal of emergency medicine, 1999. 17(4.(

13. Al-Turki, Y.A., et al., Knowledge and attitudes towards cardiopulmonary resuscitation among university students in Riyadh, Saudi Arabia. Saudi Med J, 2008. 29(9): p.9-1306. 